\title{
Exploratory Factor Analysis Research Instrument Confidence Attitude Toward Students
}

\section{noAli, Edi Istiyono, and Supahar}

Yogyakarta State Unversity, Indonesia

\section{Abstract}

This article examines the analysis of the validity of constructs on an instrument. The instrument used was a questionnaire about the students' self-confidence. This analysis is done in order to know what factors affect the attitude of confidence to students. Analysis of construct validity is done by exploratory factor analysis with the help of SPSS program version 22. Quantitative descriptive research is used in this research. The number of samples used was 50 respondents. The results of this study indicate that 1) In the exploratory factor analysis performed, the value of KMO of.588 which means

Corresponding Author: noAli

stevenalix959.2017@student .uny.ac.id

Received: 18 January 2019 Accepted: 24 March 2019 Published: 31 March 2019

Publishing services provided by Knowledge E

(c) noAli et al. This article is distributed under the terms of the Creative Commons

Attribution License, which permits unrestricted use and redistribution provided that the original author and source are credited.

Selection and Peer-review under the responsibility of the ICEST 2018 Conference Committee. the sample used as much as 50 already meet the adequacy. 2) Insufficient MSA value $>.50$ is 3,4 and 12 so it needs to be re-analyzed. The value of the MSA has qualified after the analysis without the three items. 3) Considering the value of communality $>.50$, then points 2 and 11 do not qualify with each value of 0.485 and 0.477 means it needs to be re-analyzed. After re-analyzed, the value of KMO, MSA and communal have been fulfilled. 4) Testing with exploratory factor analysis, there are 4 factors of research instrument self-confidence to the student with total variance that is explained equal to $65.806 \%$ from result of measurement. Of the four factors obtained, it can be grouped based on the factor load more than.05. Factor 1 contains points 1, 10, 13 and 17. In Factor 2 contains points 8, 14, 15 and 18. Factor 3 contains items 5, 6 and 9 and factor 4 contains items 7 and 16. Based on factor loads after rotating, naming the four factors each is courage, persistence, optimism and life challenge.

Keywords: Attitude of Confidence, Construct Validity, Exploratory Factor Analysis

\section{Introduction}

Attitude is a complex concept of psychology and many experts define it. Attitude is the response within a person, resulting in a socially significant impulse [9]. In line with Doob, Osgood, Suci, and Tannenbaum in [1] argue that attitudes refer only to the evaluative responses of mediation associated with the stimulus. 
One of the attitudes a person has is confidence. Self Confidence is self-assured in the ability and judgment (self-judgment) in doing the task and choosing an effective approach. According to Hakim, self-confidence is a belief of a person against his owned advantages so that make him feel able to achieve his purpose in life. Usually everyone has problems about confidence. Depression, economic crisis, loss of control, and cannot determine a bright future are the things that happen due to lack of confidence.

Confidence is also an attitude in relieving anxiety and feels free in doing things as desired for his actions, polite in interacting with others, have achievements, and recognize the advantages and disadvantages themselves. Confidence is also defined as an individual's self-assessment in dealing with success with demands from various situations [17]. Copeland \& Davidhizar in [5] linking self-confidence, however, is part of the professional belief.

Based on some expert opinions above can be concluded that the attitude of confidence is a response of a person to act on his belief in the face of anxiety and freedom in doing things to achieve success in various situations.

Thursan Hakim mentions some characteristics or characteristics of individuals who have a proportional confidence that is: (1) always feel calm while doing something. (2) has adequate potential and capability. (3) able to neutralize the tensions that arise in various situations. (4) able to adapt and communicate in various situations. (5) have sufficient mental and physical condition to support his performance. (6) have the ability to socialize. (7) have a life experience that forge the mental becomes strong and resistant in the face of various trials of life and (8) always react positively in the face of various problems.

In a study conducted by [11] also discussed about self-confidence by finding constructive validity to the level of confidence of nursing students. They found two factors of Clinical Decision-Making Self-Confidence Scale (CDMSCS). [12] developed a scale to measure professional confidence. They conclude that the importance of self-confidence cannot be ignored in health education because students who are learning new information and skills, and dealing with challenging situations can be adversely affected by a lack of trust that can result in students disconnecting from placement or leaving the program. The Development of self-esteem questionnaire to determine the validity of the construct was also done by [2]. They conclude that ASCQ (Ambulatory Self-Confidence Questionnaire) is useful for physicians and researchers to determine the beliefs that with their walking care abilities. 
Based on these things, the researcher intends to analyze the validity of the construct on the instrument of self confidence to the students. What factors can construct confidence will be tested on the students of Yogyakarta State University. To determine the factors, the exploratory factor analysis was analyzed.

\section{Methods}

This research uses quantitative descriptive research. Quantitative research is a study by obtaining data in the form of numbers or qualitative data that is suspected. While descriptive research is a research conducted to determine the variables or more (independent) without making comparisons. From that definition, it can be said that quantitative descriptive research is a study that is analyzed in accordance with statistical methods used and then interpreted.

Respondent's data for research instrument of self-confidence toward students was collected from students of Yogyakarta State University (YSU). From the number of YSU students, samples were taken by 50 respondents using convenience sampling. This technique is a technique that involves taking samples from individuals closest or accidentally encountered as respondents, continuing the process until the required sample size is met or until they are (what happens) available and accessible. For sample adequacy test to determine the number of factors contained in the research instrument of self-confidence to students in this study using SPSS program assistance version 22 . The sample used as many as 50 students from Yogyakarta State University.

\section{Result and Discussion}

Many experts provide insight into the validity of the instrument, both in the field of education and psychology. According to [3], validity leads to a fact and theory that supports the interpretation of test scores, and is the most important consideration in test development. The same is stated by Mardapi that the validity is the support of evidence and theory against interpretation of test scores in accordance with the purpose of the use of test.

Furthermore, [15] explain that validity refers to the adequacy and appropriateness of the interpretation and use of the assessment results. This opinion is reinforced by [14] in that the validity is an evaluative assessment of empirical facts and theoretical reasons that support the adequacy and appropriateness of conclusions and actions based on test scores. Based on some of these opinions, it can be concluded that validity refers to 
empirical data and theoretical reasons for the interpretation of test scores and related to the accuracy of measurements.

One of the validities that is often tested is the validity of the construct. The validity of constructs can be explored about the useful differences of trait and nomological validity [16]. Trait validity is investigated by considering the construct and its size according to the theory of emptiness. This means the role of theory is to describe constructs as something different from other constructs, and size validation is primarily "internal". Whereas nomological validity is based on explicit investigation of constructs and steps in terms of formal hypotheses derived from the theory (see [16]. Construct Validity can be identified by certain investigative procedures and the orientation of the investigator [8]. The first thing to do the construct validation is to identify the variables to be measured and formed based on the theory of those variables. From this theory can be seen a consequence of the measurement results to be tested. If the result is good then the instrument has a good construct validity.

Proving construct validity can be done by exploratory factor analysis. This analysis can be done manually or with the help of computer. In exploratory factor analysis manually if it has been Obtained the test data, first calculated variance-covariance matrix. After that, the Eigen value is calculated to determine the percentage of variance that can be explained. However, this analysis will be difficult if the respondent and the variables are numerous. Therefore, in this study used a computer program that is SPSS program version 22. The exploratory factor analysis using the SPSS program begins by testing the sample adequacy to calculate the Eigen values. This value is used to calculate the percentage of variance described and draw the scree plot.

Table 1 shows the results of the Kaiser Meyer Olkin (KMO) test and the MSA (Measures of Sampling Adequacy) score. According to Hair et. al and Tabachnick et al. the KMO index ranges from 0 to 1, with.50 considered suitable for factor analysis [19]. From the results in table 8 obtained $\mathrm{KMO}$ values of.588 in this case the value of $\mathrm{KMO}$ is greater.50. This means that the number of samples used in testing or retrieval of data is sufficient or eligible for further factor analysis.

Furthermore, the required MSA value of at least $>.50$ for the variables can still be predicted and can be further analysis. Measure of Sampling Adequacy will be good and minimum acceptable level limit.50 $[4,13]$. Table 1 shows that the MSA value of the correlation anti-image is not sufficient for MSA >.50 is item 3,4 and 12. This indicates that it needs to be re-analyzed without using item 3, 4 and 12 .

Results of re-analysis without using 3, 4 and 12 indicate that the KMO value increased to 0.691 so that the condition is still fulfilled. The results are presented in table 2 . The 
TABLE 1: MSA and KMO values on self-confidence instruments.

\begin{tabular}{|c|c|c|}
\hline Item & MSA & $\mathrm{KMO}$ \\
\hline Item 1 & .654 & .588 \\
\hline Item 2 & .558 & \\
\hline Item 3 & .474 & \\
\hline Item 4 & .341 & \\
\hline Item 5 & .528 & \\
\hline Item 6 & .511 & \\
\hline Item 7 & .655 & \\
\hline Item 8 & .614 & \\
\hline Item 9 & .596 & \\
\hline Item 10 & .614 & \\
\hline Item 11 & .623 & \\
\hline Item 12 & .452 & \\
\hline Item 13 & .570 & \\
\hline Item 14 & .808 & \\
\hline Item 15 & .615 & \\
\hline Item 16 & .786 & \\
\hline Item 17 & .684 & \\
\hline Item 18 & .523 & \\
\hline
\end{tabular}

MSA value for all independent variables has met the requirement of $>.50$, meaning that the analysis can be done further.

Table 3 shows the value of the communality of each extracted item. The communality of an item is said to be "high" if the value is.80 and "very low" if its value is.40 [18]. According to [7] the desired communal value of.50 or greater indicates a solid factor. With further research and analysis it is possible to reduce the quantity of goods and maintain a strong factor; if there is a huge data set.

Based on the results in table 3, repeated step factor analysis from the beginning without including 2 and 11 by considering the value of communality less than.50. After a re-analysis, assuming that the KMO and MSA values in the previous step have been met then in this step the values must have been met. The table also shows the results of the value of communality on each item has been eligible. Thus, further analysis can be done to calculate the Eigen values.

Next, calculate the Eigen values as well as the percentage of variance explained against the factor. In component analysis, the commonly used rule is that the Kaiser 
TABLE 2: MSA and KMO values after reanalysis.

\begin{tabular}{|l|l|l|}
\hline Item & MSA & KMO \\
\hline Item 1 & .736 & .691 \\
\hline Item 2 & .709 \\
\hline Item 5 & .626 \\
\hline Item 6 & .679 \\
\hline Item 7 & .676 \\
\hline Item 8 & .621 \\
\hline Item 9 & .563 \\
\hline Item 10 & .731 \\
\hline Item 11 & .782 \\
\hline Item 13 & .603 \\
\hline Item 14 & .785 \\
\hline Item 15 & .732 \\
\hline Item 16 & .787 \\
\hline Item 17 & .756 \\
\hline Item 18 & .596 \\
\hline
\end{tabular}

rule of Eigen values is greater than $1[10,20,21]$. Table 4 presents the results of factor rotation analysis and the total value of the variance described. These results indicate that there are 4 Eigen values greater than 1 so that it can be said that the instrument of self-confidence to students contains 4 factors. With these 4 factors, the instrument can account for $65.806 \%$ of the measurement variance.

The number of factors contained in an instrument can also be seen from the scree plot shown in Figure 1. The extracted factor explains the low variance and decreased steep Eigen value indicating how many factors must be determined or maintained [6, 21].

Considering the result of the scree plot of Figure 1, it appears that the eigenvalue starts to ramp in the 5th factor and there is one dominant factor and the other 3 factors also contribute substantially to the component of the variance which can be explained. So, it can be concluded that the instrument of self-esteem attitude towards the students at least measure 4 factors.

After knowing the many measurable factors on the instrument, then do the naming factor by looking at the load factor that has been rotated using a criteria factor significant of.5. The naming of the factors contained in the instrument is done with the help of experts in the field. Table 4 shows that the items contained in factor 1 are items 1, 10, 13, and 17. In Factor 2 contains items 8, 14, 15 and 18. Factor 3 contains 5, 6, and 9 
TABLE 3: The value of the communality of each item.

\begin{tabular}{|l|c|c|c|c|c|}
\hline & \multicolumn{2}{c}{ Communalities } & & \multicolumn{2}{c}{ Communalities re-Analysis } \\
\hline & Initial & Extraction & & Initial & Extraction \\
\hline Item 1 & 1.000 & .506 & Item 1 & 1.000 & .561 \\
\hline Item 2 & 1.000 & .485 & - & - & - \\
\hline Item 5 & 1.000 & .520 & Item 5 & 1.000 & .535 \\
\hline Item 6 & 1.000 & .511 & Item 6 & 1.000 & .526 \\
\hline Item 7 & 1.000 & .725 & Item 7 & 1.000 & .730 \\
\hline Item 8 & 1.000 & .687 & Item 8 & 1.000 & .708 \\
\hline Item 9 & 1.000 & .725 & Item 9 & 1.000 & .713 \\
\hline Item 10 & 1.000 & .719 & Item 10 & 1.000 & .699 \\
\hline Item 11 & 1.000 & .477 & - & - & - \\
\hline Item 13 & 1.000 & .550 & Item 13 & 1.000 & .657 \\
\hline Item 14 & 1.000 & .660 & Item 14 & 1.000 & .650 \\
\hline Item 15 & 1.000 & .797 & Item 15 & 1.000 & .798 \\
\hline Item 16 & 1.000 & .566 & Item 16 & 1.000 & .595 \\
\hline Item 17 & 1.000 & .665 & Item 17 & 1.000 & .664 \\
\hline Item 18 & 1.000 & .713 & Item 18 & 1.000 & .719 \\
\hline
\end{tabular}

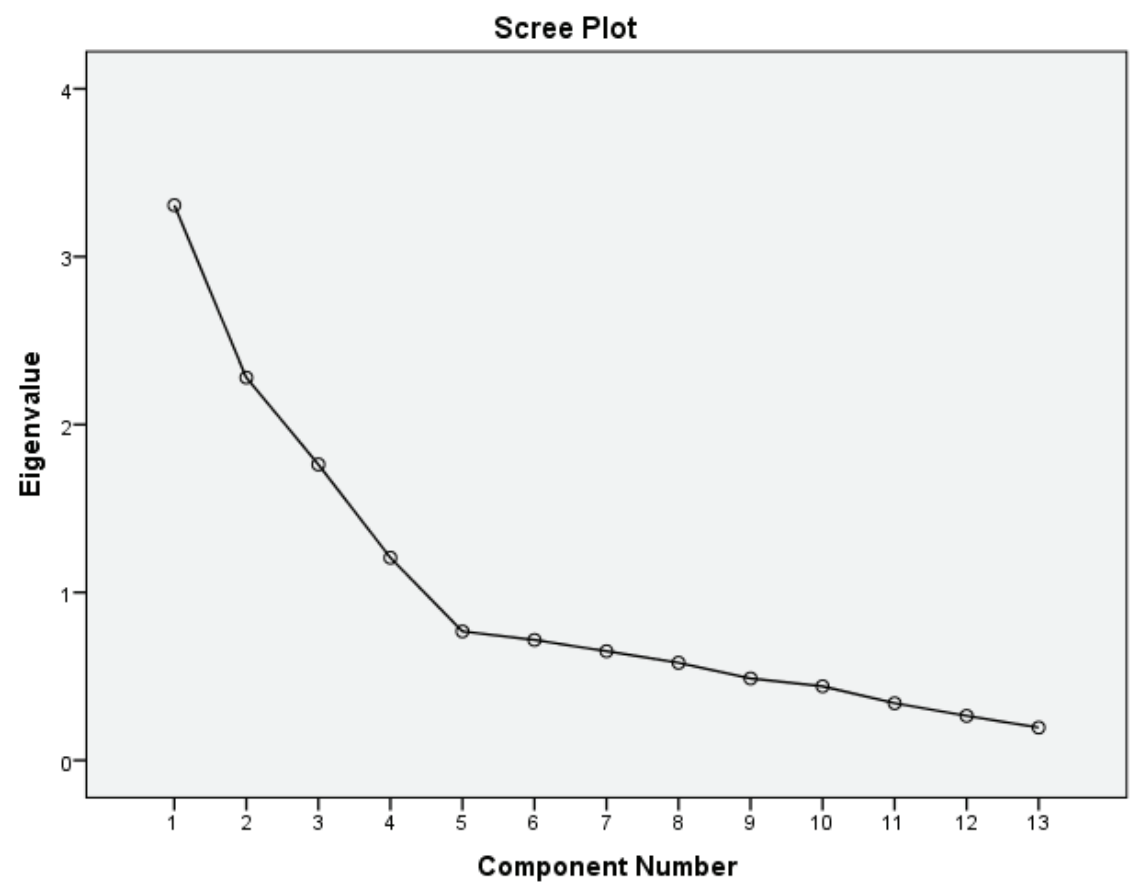

Figure 1: Scree Plot result of exploratory factor analysis.

items and a factor of 4 contains points 7 and 16. The naming of each factor in factor 1 is 
TABLE 4: The irradiated factors and the total value of the variance explained.

\begin{tabular}{|c|c|c|c|c|}
\hline \multicolumn{5}{|c|}{ Rotated Component Matrix ${ }^{a}$} \\
\hline & \multicolumn{4}{|c|}{ Component } \\
\hline & 1 & 2 & 3 & 4 \\
\hline Item 1 & .739 & .103 & -.047 & .040 \\
\hline Item 5 & -.078 & .119 & .716 & -.041 \\
\hline Item 6 & -.079 & .181 & .691 & .097 \\
\hline Item 7 & .059 & .206 & .195 & .804 \\
\hline Item 8 & .314 & .695 & -.328 & .136 \\
\hline Item 9 & .159 & -.123 & .820 & -.008 \\
\hline Item 10 & .715 & .396 & -.175 & -.018 \\
\hline Item 13 & .726 & -.114 & .332 & .082 \\
\hline Item 14 & .299 & .596 & .345 & -.294 \\
\hline Item 15 & .013 & .754 & .353 & .326 \\
\hline Item 16 & .245 & .111 & -.140 & .709 \\
\hline Item 17 & .745 & -.054 & -.069 & .318 \\
\hline Item 18 & -.130 & .807 & .085 & .211 \\
\hline Eigen value & 3.306 & 2.280 & 1.762 & 1.206 \\
\hline Variance (\%) & 25.434 & 17.537 & 13.556 & 9.279 \\
\hline $\begin{array}{l}\text { Cumulative of } \\
\text { variance (\%) }\end{array}$ & 25.434 & 42.971 & 56.527 & 65.806 \\
\hline
\end{tabular}

called courage because the factor's load is related to one's courage. Factor 2 is called persistence because the charge factor is related to the nature of firmness in one's stand. Factor 3 is called optimistic because the factor load is related to the optimistic sense of self. Factor 4 is called the life challenge because the charge factor is related to the problem in life.

\section{Conclusion}

This article proves the validity of the construct on the instrument of self-confidence towards students. On the validity of construct validity is done by exploratory factor analysis with the help of SPSS program version 22 . The analysis starts from testing the adequacy of the sample at KMO test $>.50$. In exploratory factor analysis conducted, the value of KMO of.588 that means the sample used as much as 50 already meet the adequacy. To see the correlation between variables, we can see the value of MSA in the anti-image correlation. Insufficient MSA value $>.50$ is 3,4 and 12 so it needs to be 
re-analyzed. Once re-analyzed, the value of MSA has met the requirement which means the analysis can be continued.For further analysis, it can be seen again komunalitas on variables with the value of komunal $>.50$ results indicate that items 2 and 11 do not meet the requirements with each value of.485 and.477. thus re-analyzing again. After re-analyzed the results showed that the value of KMO, MSA and communality has been fulfilled which means the analysis can be continued

The number of factors is known by looking at more than 1 eigen values. In the test of this exploratory factor analysis results, the analysis shows there are 4 eigen values more than 1. With these 4 factors, the instrument has explained $65.806 \%$ of the measurement variance. Based on the result of factor load after rotation, it can be grouped on factor 1 containing points 1, 10, 13 and 17. On factor 2 contains points $8,14,15$ and 18 . Factor 3 contains items 5, 6 and 9 and factor 4 contains items 7 and 16. Based on the factor's contents after the rotation, the naming of the four factors is each called courage, persistence, optimism and life challenge.

\section{Acknowledgement}

Researchers would like to thank the participants who contributed to the fulfillment of research data needs. no additional funding from outside other than researchers in this project.

\section{References}

[1] Anderson, L. R., \& Fishbein, M. (1965). Prediction of attitude from the number, strength, and evaluative aspect of beliefs about the attitude object: A comparison of summation and congruity theories. Journal of Personality and Social Psychology, 2(3), 437-443.

[2] Asano, M., Miller, W. C., \& Eng, J. J. (2008). Development and psychometric properties of the ambulatory self-confidence questionnaire. Gerontology, 53(6), 373-381.

[3] Association, A. E. R., Association, A. P., Education, N. C. on M. in, Educational, J. C. on S. for, \& (US), P. T. (1999). Standards for educational and psychological testing. Amer Educational Research Assn.

[4] Bagby, R. M., Parker, J. D. A., \& Taylor, G. J. (1994). The twenty-item Toronto Alexithymia scale-I. Item selection and cross-validation of the factor structure. Journal of Psychosomatic Research, 38(1), 23-32. 
[5] Brown, B., O’Mara, L., Hunsberger, M., Love, B., Black, M., Carpio, B., ... Noesgaard, C. (2003). Professional confidence in baccalaureate nursing students. Nurse Education in Practice, 3(3), 163-170.

[6] Cattell, R. B. (1966). The scree test for the numbers of factors. Multivariate Behavioral Research, 1(August), 245-276.

[7] Costello, A. B., \& Osborne, J. W. (2005). Best Practices in Exploratory Factor Analysis: Four Recommendations for Getting the Most From Your Analysis. Practical Assessment, Research \& Education, 10, 1-9.

[8] Cronbach, L. J., \& Meehl, P. E. (1955). Construct validity in psychological tests. Psychological Bulletin, 52(4), 281.

[9] Doob, L. W. (1947). The behavior of attitudes. Psychological Review, 54(3), 135-156.

[10] Eaton, C. A., Velicer, W. F., \& Fava, J. F. (1998). Determining the number of components: An evaluation of alternative procedures. Manuscript Submitted for Publication.

[11] Hart, P. L., Spiva, L., \& Mareno, N. (2014). Psychometric Properties of the Clinical Decision-Making Self-Confidence Scale. Journal of Nursing Measurement, 22(2), 312-322.

[12] Hecimovich, M. D., Styles, I., \& Volet, S. E. (2014). Development and psychometric evaluation of scales to measure professional confidence in manual medicine: $A$ Rasch measurement approach. BMC Research Notes, 7(1), 1-14.

[13] Kaiser, H. F., \& Rice, J. (1974). Little Jiffy, Mark Iv. Educational and Psychological Measurement, 34(1), 111-117.

[14] Messick, S. (1987). Validity. ETS Research Report Series, 1987(2).

[15] Miller, M. D., Linn, R. L., \& Norman E. Gronlund. (2009). Measurement and Assessment in Teaching (10th ed.). New Jersey: Pearson.

[16] Peter, J. P. (1981). Construct validity: A review of basic issues and marketing practices. Journal of Marketing Research, 133-145.

[17] Shrauger, J. S., \& Schohn, M. (1995). Self-confidence in college students: Conceptualization, measurement, and behavioral implications. Assessment, 2(3), 255-278.

[18] Velicer, W. F., \& Fava, J. L. (1998). Affects of variable and subject sampling on factor pattern recovery. Psychological Methods, 3(2), 231-251.

[19] Williams, B., Onsman, A., \& Brown, T. (2010). Exploratory factor analysis: A five-step guide for novices. Australasian Journal of Paramedicine, 8(3).

[20] Zwick, W. R., \& Velicer, W. F. (1982). Factors influencing four rules for determning the number of components to retain. Multivariate Behavioral Research, 17(January 2014), 253-269. 
[21] Zwick, W. R., \& Velicer, W. F. (1986). Comparison of Five Rules for Determining the Number of Components to Retain. Psychological Bulletin, 99(3), 432-442. 